\title{
Les experts
}

D’après le Quotidien $d u$ pharmacien du 13 juillet, des sénateurs souhaitent recréer la profession d'herboriste. Ces derniers ont présenté le 12 juillet une proposition de loi destinée à " créer et à organiser la profession d'herboriste ", supprimée en 1941 sous Pétain. L'objectif serait de mieux protéger les consommateurs et d'éviter le développement de la vente sans contrôle des plantes sur les marchés, sur Internet ou par l'étranger. Actuellement, 148 plantes peuvent être vendues librement, hors du monopole pharmaceutique et souvent sans contrôle.

En phytothérapie, le chemin de la plante au médicament est complexe. Utiliser les « Simples » est très compliqué. Ce chemin

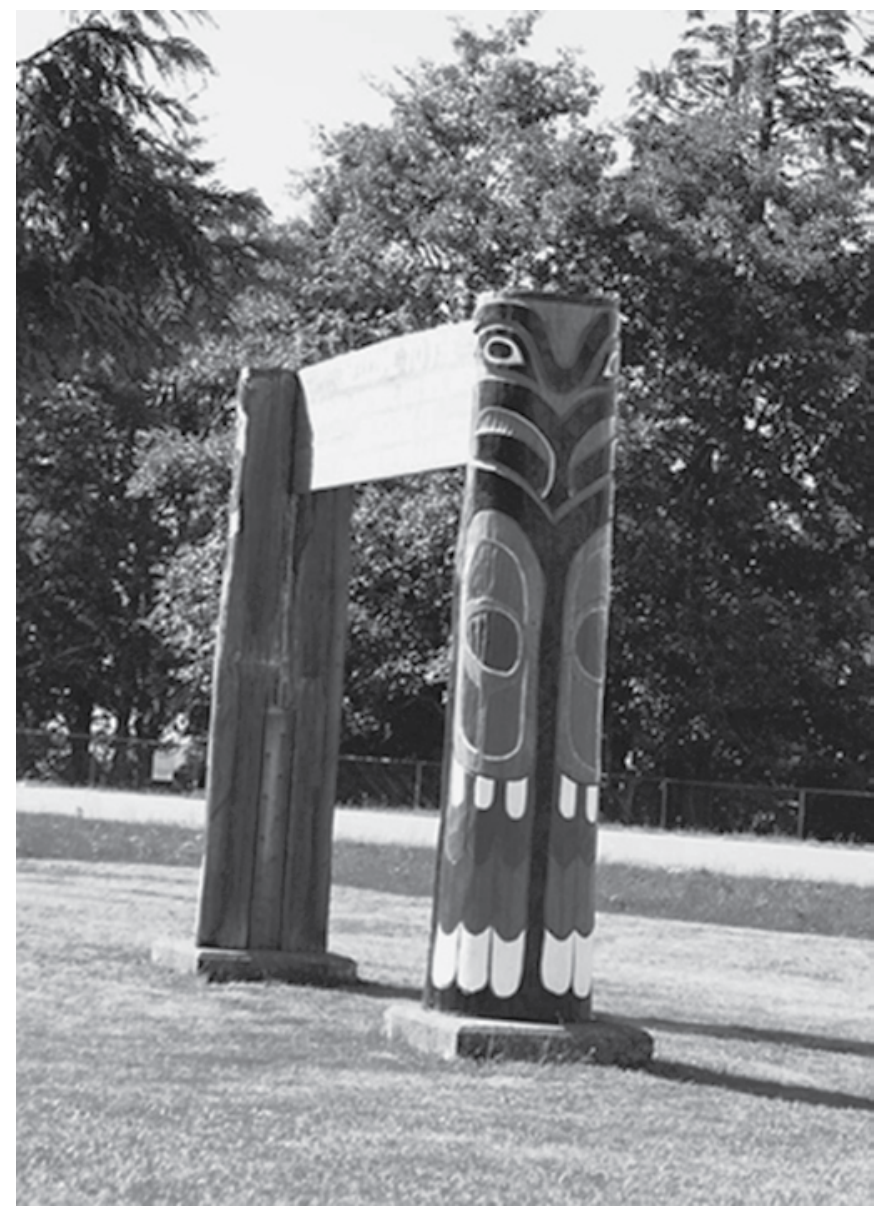

Portique en totem de Neah Beach du Makah Cultural and Research Center va du cueilleur ou de l'agriculteur spécialisé à la prescription et à la délivrance en pharmacie ou en un lieu où un spécialiste de ce type de substance est « autorisé » officiellement à le faire.

Je suis encore sous l'influence de mon séjour aux États-Unis, et en particulier en cet endroit insolite qu'est la pointe extrême de l'État de Washington, à Neah Beach, la réserve indienne des Makah ${ }^{1}$, Indiens du groupe Nootka. Ces Indiens de la Côte Ouest, grands chasseurs de baleine, étaient comme leurs voisins, au contact de la plante, au-delà de ce que nous pouvons imaginer. En effet, au contraire d'autres nations indiennes, ils navaient pas de vêtements en peau d'animal, mais fabriqués à base de l'écorce de Thuja plicata (western red cedar), travaillée de manière à obtenir des lanières assemblées en "tissus ». Rien de plus expert que ce contact direct avec 
le monde végétal. Il est possible de voir au Makah Cultural and Research Center de Neah Beach la façon extrêmement habile et experte avec laquelle ils utilisèrent les plantes.

Les experts en phytothérapie sont ceux qui ont le contact le plus proche avec la plante médicinale. La phytothérapie en tant que thérapie doit s'appliquer à une pathologie, c'est le travail du médecin phytothérapeute, c'est aussi la recherche de la drogue (partie utilisée de la plante) la plus véritable, l'élimination des déchets, la traque des falsifications, pour obtenir les drogues les plus pures (sans pesticides, etc.). Cela est du ressort des herboristes dans leur rôle avec les simples qu'ils connaissent, conservent et délivrent selon la tradition la plus pure. Les pharmaciens d'aujourd'hui peuvent encore faire preuve d'intérêt pour les plantes, mais beaucoup d'entre eux n'ont aucune notion de phytothérapie. C'est donc également la création d'un titre de pharmacien spécialisé en phytothérapie qu'il faut réinventer. Formons donc à nouveau des herboristes avec des notions médicales (comme le fait le Dumenat de phytoaromathérapie de Paris-XIII) ! Que la mémoire vivante des enseignants se perpétue.

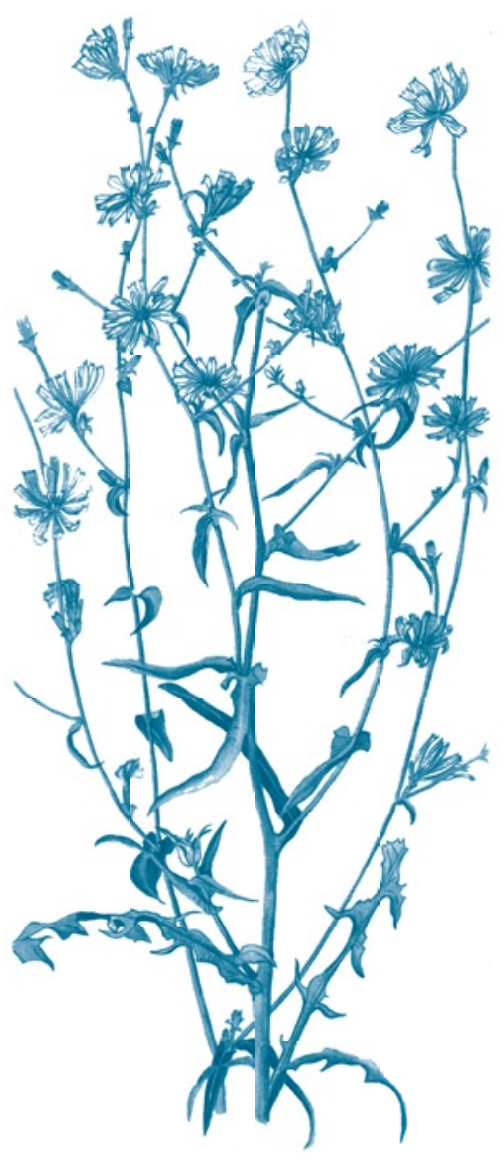

